\title{
More rapid identification of bacteraemia by manual rather than radiometric method
}

\author{
LEELA A GANGULI, MAEVE GL KEANEY, WA HYDE, SUSAN B FRASER \\ From the Department of Microbiology, Hope Hospital, University of Manchester School of Medicine, Salford
}

SUMMARY Results of blood culture examination using the radiometric (Bactec-460) system for one year showed no overall improvement compared with those of the previous three years when a $\vec{\sigma}_{\sigma}$ manual system with early blind subculture was used. The isolates from the manual system were $\frac{0}{8}$ available more often on solid media, 24 hours earlier, than when the radiometric system was $\dot{\omega}_{\text {a }}$ used. In a further study of 1100 blood cultures the radiometric medium was tested for growth index as well as being subcultured blindly, irrespective of growth index, on the first day. Thirty six out of $54(67 \%)$ of the blood cultures were positive on subculture but negative for growth index at this time. The overall cost of the radiometric system is also considerably more than that of the manual system.

Detection of bacteraemia by means of the semiautomated radiometric Bactec-460 system (Johnston Laboratories, United States) is increasingly being accepted as a routine procedure in clinical laboratories. It is reported as being faster and more sensitive than manual methods. ${ }^{2}$ We analysed the time taken to detect bacteraemia using the Bactec system for one year and compared this with data from the previous three years when a manual system was used that included early blind subcultures. We also present results of a prospective study comparing the radiometric and conventional blood culture detection systems in parallel.

\section{Material and methods}

\section{CULTURE MEDIA}

Bactec media phials $6 \mathrm{~B}$ and $7 \mathrm{C}$ were used as aerobic and anaerobic media in the radiometric system. The media used in our conventional system were as reported previously ${ }^{3}$ : they consisted of a biphasic aerobic medium with Columbia agar (Lab M, Salford) as the solid phase and brain-heart infusion broth (Lab M) containing polyanethol sulphonate (Liquoid, Roche) $0.25 \%$ and thymidine (BDH) $0.4 \%$ as the liquid phase. The anaerobic medium used was fastidious anaerobe broth (FAB, Lab M). The volume of blood cultured in both systems was similar.

\section{SUBCULTURES}

Bactec media were used in accordance with the $\frac{\mathbb{D}}{-}$ manufacturer's instructions but with an additional $\overrightarrow{0}$ test at $10 \mathrm{pm}$ on the first day. Aerobic phials wegeco tested three times on the day the sample was received in the laboratory (day 1). Cultures takêino between $5 \mathrm{pm}$ and 9 am were tested at 9 am and 4 S pm. Cultures received between 9 am and $5 \mathrm{pm}$ were tested at $10 \mathrm{pm}$. All cultures, including anaerobic $\frac{\%}{\varnothing}$ phials, were tested twice on day 2 , at 9 am and $4 \mathrm{pm}, \stackrel{\varrho}{\rightarrow}$ and once on days 3,4 , and 7 . We omitted testing on days 5 and 6 as a previous investigation had shown this to be less useful. Blood cultures taken between $5 \mathrm{pm}$ and 9 am were incubated without delay in incubators within easy reach of medical staff ando collected by laboratory staff at $9 \mathrm{am}$. A growth index:$\geqslant 30$ in the aerobic phial and $\geqslant 15$ in the anaerobic 3 . phial, or a rise of $\geqslant 10$ between two consecutive readings in either bottle, was considered to be positive, and a Gram film and subculture were made.

We used the routine previously described for our? manual system with early blind subculture. Cultureso were examined visually at 9 am each day. The biphasic medium was subcultured twice by tilting, $O$ and, in addition, the fastidious anaerobic brothn medium was subcultured blind at $10 \mathrm{pm}$ on day 1 .N Further blind subcultures of fastidious anaerobic ${ }_{\sigma}^{\omega}$ broth were performed at 9 am on days 2,4 , and 72 when finally, both bottles were opened and subcultured. Reporting times in the manual system weres based on microscopy or results of blind subcultures and those for the Bactec on growth index readings and microscopy. 
Table 1 Time taken to detect patients with bacteraemia (1980-83)

\begin{tabular}{|c|c|c|c|c|}
\hline & \multicolumn{3}{|c|}{ Manual system } & \multirow{2}{*}{$\frac{\text { Bactec system }}{1983}$} \\
\hline & 1980 & 1981 & 1982 & \\
\hline $\begin{array}{l}\text { No of blood culture sets } \\
\text { No of patients examined } \\
\text { No of patients with bacteraemia (\%) } \\
\text { Reported by } 10 \mathrm{pm} \text { day } 1 \\
\text { Positive after blind subculture on day } 1 \\
\text { Growth on solid medium within } 24 \text { hours } \\
\text { Additional positives at } 9 \text { am, day } 2 \\
\text { Total reported in } 24 \text { hours }\end{array}$ & $\begin{array}{r}3282 \\
1515 \\
117 \\
16(14) \\
48(41) \\
64(55) \\
14(12) \\
78(67)\end{array}$ & $\begin{array}{r}3749 \\
1656 \\
120 \\
23(19) \\
32(27) \\
55(46) \\
34(28) \\
89(74)\end{array}$ & $\begin{array}{l}4820 \\
2071 \\
171 \\
35(21) \dagger \\
55(32) \\
90(53) \ddagger \\
44(26)^{*} \\
134(78)^{* *}\end{array}$ & $\begin{array}{l}6411 \\
3249 \\
207 \\
73(35) \dagger \\
\text { ND } \\
73(35) \ddagger \\
98(47)^{*} \\
171(83)^{* *}\end{array}$ \\
\hline
\end{tabular}

$\mathrm{ND}=$ not done.

Significance $\dagger p<0.01, \ddagger<0.025,{ }^{*}<0.001,{ }^{* *}$ not significant.

Table 2 Comparison of blind subculture and growth index reading in 1100 radiometric blood cultures

\begin{tabular}{lllll}
\hline & Positive at & & Total (\%) \\
\cline { 2 - 5 } & $4 \mathrm{pm}$ & $7 \mathrm{pm}$ & $10 \mathrm{pm}$ & \\
\hline Subculture positive but growth index negative & 9 & 5 & 22 & $36(67)^{*}$ \\
Both methods positive & 9 & 3 & 6 & $18(33)^{*}$ \\
Total of positive cultures & 18 & 8 & 28 & 54 \\
\hline
\end{tabular}

*Significance $\mathrm{p}<0.05$.

In the subsequent comparative study of 1100 blood cultures the aerobic $6 \mathrm{~B}$ phial was subcultured blindly irrespective of growth index readings and tested as shown above on day 1 . Cultures received between $5 \mathrm{pm}$ and 9 am were subcultured at $4 \mathrm{pm}$ (seven to 23 hours of incubation), and those received between 9 am and $5 \mathrm{pm}$ were subcultured at $10 \mathrm{pm}$ (five to 13 hours of incubation). During the weekend and on bank holidays blind subcultures were done at $7 \mathrm{pm}$ only. The Bactec $6 \mathrm{~B}$ phials were also tested for growth index readings at these times.

\section{Results}

Table 1 shows the time taken to detect clinically important bacteraemia in patients during four consecutive years. In 1982, using our manual system, we reported 90 out of $171(53 \%)$ cases of bacteraemia on the basis of cultures on a solid medium within 24 hours. This figure is similar to that in our previously reported study. ${ }^{3}$ The corresponding figure in 1983, using the Bactec, was only 73 out of $207(35 \%)$. This difference is significant. Taking the additional sample for radiometry at $10 \mathrm{pm}$ on the first day, which is not a recommended procedure for Bactec, $23(11 \%)$ more positive results were reported. The total detection rate by the Bactec system as reported by $10 \mathrm{pm}$ on day 1 was $35 \%$ compared with $21 \%$ for the manual system ( $p<0.01)$. The figure of $35 \%$ includes results from a sampling at $4 \mathrm{pm}$ and $10 \mathrm{pm}$ using the Bactec system. We did not subculture at $4 \mathrm{pm}$ with the manual system. Most positive cultures recorded by the Bactec system were detected radiometrically at 9 am on day 2 , at which time a tentative result based on microscopy only was possible. The total detection rate over 24 hours using Bactec did not differ significantly from that in the previous year using the manual system.

In the comparative parallel study 1100 radiometric blood cultures were examined and 54 found to be positive. In $36(67 \%)$ of these the Bactec bottles were positive after blind subculture but negative for growth index on day 1 (Table 2). The organisms isolated from the 36 radiometric blood cultures are shown in Table 3 . These cultures gave a positive growth index reading the next morning at 9 am (11 to 17 hours later), at which time growth was visible on subcultured plates.

Table 3 Organisms isolated from 36 blood cultures positive on subculture but negative for growth index

\begin{tabular}{ll}
\hline Organisms & No of isolations \\
\hline Staphylococcus aureus & 8 \\
Staphylococcus epidermidis & 4 \\
Streptococcus spp (Lancefield group D) & 5 \\
Escherichia coli & 4 \\
Klebsiella aerogenes & 4 \\
Serratia marcescens & 3 \\
Streptococcus pneumoniae & 1 \\
Morganella morganii & 1 \\
Proteus mirabilis and Escherichia coli & 1 \\
Proteus mirabilis and Staphylococcus aureus & 1 \\
Streptococcus mitis & 1 \\
*Serratia sp and Klebsiella ozaenae & 1 \\
*Serratia sp and Acinetobacter calcoaceticus var & 1 \\
anitratus & Klebsiella oxytoca and Acinetobacter \\
calcoaceticus var anitratus & 1 \\
\hline Total & 36 \\
\hline
\end{tabular}

*Probable contaminants. 
Table 4 Comparison of approximate annual costs (f) for 6411 blood culture sets*

\begin{tabular}{|c|c|c|c|c|}
\hline \multicolumn{2}{|l|}{ Manual system } & \multicolumn{3}{|l|}{ Bactec system } \\
\hline $\begin{array}{l}\text { Fastidious anaerobe broth medium } \\
\text { Biphasic medium } \\
\text { Medical laboratory scientific officer ( } 1 \text { ) } \\
\text { Laboratory assistants (11/2) } \\
\text { Subculture at } 10 \mathrm{pm} \text { "on call" } ¥ \\
\text { Four "blind" subcultures }\end{array}$ & $\begin{array}{l}3213 \dagger \\
2127 \\
8162 \\
6764 \\
3041 \\
3044\end{array}$ & $\begin{array}{l}\text { 6B } \\
\text { 7D } \\
\text { Medical laboratory scientific officer (1) } \\
\text { Subculture at } 10 \mathrm{pm} \text { "on call" } \ddagger \\
\text { Leasing charge } \\
\text { Bactec capital depreciation } \S \\
\text { Maintenance } \\
\text { Bottle crusher depreciation } \S\end{array}$ & $\begin{array}{l}\text { Leased } \\
7234 \\
7234 \\
8162 \\
\\
3041 \\
7320 \\
\\
1452 \\
200\end{array}$ & $\begin{array}{l}\text { Purchased } \\
7234 \\
7234 \\
8162 \\
\\
3041 \\
4774 \\
1452 \\
200\end{array}$ \\
\hline Total & 26351 & & 34643 & 32097 \\
\hline
\end{tabular}

*Prices at April 1985 include VAT, exclude laboratory overheads.

tIncludes current discount and delivery charge.

$¥$ At $£ 8.33$ per day.

\$Over five years.

\section{Discussion}

The rapid rise in the number of laboratories-now more than 100 in the United Kingdom ${ }^{4}$ - using the radiometric semiautomated Bactec- 460 system reflects the documented conception that this system is more efficient than conventional methods and also saves the time of technical staff. We agree that the semiautomation makes sampling quicker and less tedious when dealing with large numbers of cultures. Published reports of the superiority of the radiometric system are based on comparative data using a manual system with inadequate media and few or no early blind subcultures. ${ }^{256}$ Thus in a recent study a very low detection rate of $9.5 \%$ (at 24 hours with the manual system) rose to $76 \%$ with the Bactec system. ${ }^{2}$ Our considerably higher manual detection rate of $78 \%$ may be due to the use of an efficient biphasic aerobic medium in parallel with a sensitive anaerobic medium, incubation without delay outside laboratory hours, and early blind subculturing.

A comparison of the radiometric with conventional blood culture systems depends on the adequacy of each system, and both continue to be improved. In our experience reporting times were similar with the manual and the radiometric systems. Our preference for early blind subculturing is because the isolate is then available on solid medium 24 hours earlier than with the Bactec system. This enables preliminary identification and the choice of a more specific, narrower spectrum antibiotic. A blind early subculture of Bactec 6B phials gives quicker results than radiometric detection but defeats the purpose of semiautomation.

We observed Bactec phials showing negative growth indexes yet with visual evidence of heavy bacterial growth, including a carpet of colonies and turbidity and numerous organisms on microscopy.
This emphasises the importance of critical visuaiexamination with the Bactec as with all other bloods culture systems. This was most evident in theo unshaken anaerobic bottles. In aerobic bottles $?$ however, the recommended use of the shaker in the first 24 hours obscured this effect, although the? shaker often proved to be mechanically unreliable음 Conclusive evidence of the relative insensitivity of the radiometric system was provided by the resultso of our prospective parallel study of 1100 blood col $1-0$ tures, when $67 \%$ of the positives on the first de were negative for growth index.

Table 4 shows that the costs of investigating 64.11 blood culture sets by the Bactec system are consid-a erably higher than those of our manual system. This isD despite estimations for a generous amount of staff time for preparing biphasic medium and doing blind subscultures in the manual system. The comparative costs reported from the United States show the Bac tec system to be relatively even more expensive. ${ }^{\prime}$

Further disadvantages of the Bactec are the smaln maximum volume $(3-5 \mathrm{ml})$ of blood cultured, the dependence on American media, the use of radioac tive materials (although of low intensity), and the economic burden of being tied to the United States exchange rate. Despite these important disadvan-o tages semiautomation is an attractive feature of the Bactec system because it facilitates the handling of large numbers of specimens.

We conclude that the overall detection rate with? the Bactec-460 system, though convenient, is nos better than that with our manual system. Moreover N the radiometric detection system is comparativelyo insensitive as, in the absence of a significant growth index, early blind subculture yields positive result on solid media.

An interesting modification incorporated in theo new Bactec NR-660 is the replacement of the radiometric by an infrared detection system. Thi 
new system, however, still depends on adequate production of gas, and its sensitivity has yet to be evaluated.

We thank all the staff of the Microbiology Department for their help, Mr David Matthews for his statistical analysis, and Mrs M Marriott for typing the manuscript.

\section{References}

' Strand CL, Jones MC, Daniel WW. Comparison of a radiometric and a conventional blood culture system: efficiency of recovery, speed of recovery, cost and technical time. Lab Med 1980;11:41-6.

${ }^{2}$ Corkill JE. Effects of media, working practice and automation on the rapid detection of bacteraemia. J Clin Pathol 1985; 38:336-40.

${ }^{3}$ Ganguli LA, O'Hare W, Hyde WA. Rapid detection of bacteraemia by early subculture. J Med Microbiol 1984;17:311-5.

4 Anonymous. Six Bactecs for North West Thames. Medical Technologist 1985; 15 (3): 11 .

${ }^{5}$ Brooks K, Sodeman T. Rapid detection of bacteremia by a radiometric system. A clinical evaluation. Am J Clin Pathol 1974;61:859-66.

${ }^{6}$ Randall EL. Long-term evaluation of a system for radiometric detection of bacteremia. In: Schlessinger D, ed. Microbiology. Washington DC: American Society for Microbiology 1975:39-44.

Requests for reprints to: Dr LA Ganguli, Department of Microbiology, Hope Hospital, Eccles Old Road, Salford M6 8HD, England. 